\title{
The slope creep law for a soft rock in an open-pit mine in the Gobi region of Xinjiang, China
}

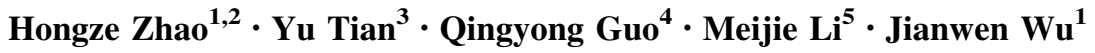

Received: 27 June 2019/Revised: 23 December 2019/Accepted: 20 February 2020/Published online: 5 March 2020

(C) The Author(s) 2020

\begin{abstract}
The lithology of the strata in the Gobi region of the Xinjiang autonomous region of China is mainly composed of mudstone, silty mudstone, and other soft rocks. Because of the low strength of the rock mass and the serious effects of physical weathering in this area, the slope stability in open-pit mines is poor, and creep deformation and instability can readily occur. Taking the Dananhu No. 2 open-pit mine as a typical example, the creep test of a mudstone sample under different stress levels was studied. Then, based on a bottom friction experiment and a FLAC3D numerical simulation, the deformation and failure processes of the slope were analyzed. The stress-displacement curve and the displacement-time curve for the monitoring points were plotted to obtain the relationship between the stress and displacement for the slope of the soft rock. The results showed that the long-term strength of the mudstone was between 8.0 and $8.8 \mathrm{MPa}$, and that stable creep occurred when the slope was under low stress. The potential failure mode for this type of slope is that the front edge creeps along the weak layer and then a crack is formed at the trailing edge of the slope. When the crack penetrates the weak layer, cutting bedding and bedding sliding occur. The deformation process of the stable creep slope includes an initial deformation stage, an initial creep stage, a constant velocity creep stage and a deceleration creep stage.
\end{abstract}

Keywords Gobi region · Soft rock slope $\cdot$ Numerical simulation · Creep deformation · Creep experiment

\section{Introduction}

Soft rock is widely distributed in China. Given a relative depletion of shallow resources in the country, the depth and scale of open-pit mining have been increasing recently

Hongze Zhao

hzzhao78@163.com

1 School of Energy and Mining Engineering, China University of Mining and Technology, Beijing, Beijing 100083, China

2 State Key Laboratory for Geomechanics and Deep Underground Engineering, China University of Mining and Technology, Beijing, Beijing 100083, China

3 China Coal Xi' an Design Engineering Co., Ltd. Shanxi, Xi' an 710054, China

4 Shenhua Geological Exploration Co., Ltd, Beijing 102209, China

5 North Blasting Technology Co., Ltd., Beijing 100083, China such that soft rock slopes are exposed and soft rock landslides may occur. The deformation and instability of soft rock slopes are usually accompanied by the occurrence of creep. Due to the complex and diverse nature of the engineering geological conditions, together with the formation, deformation, instability and other induced factors, the creep slope has become an active research field in the mining industry in recent years (Yang et al. 2003; Fan and Gao 2007; Tan et al. 2010; Xu 2017).

For a sustained period, researchers in China have studied creep deformation and the instability mechanism (Wang 2009; Wang et al. 2010) in soft rock slopes, and also the failure mechanisms (Li et al. 1998; Wang et al. 2013) and reinforcement and treatment measures (Wang et al. 2007). These studies have provided a theoretical basis for the prevention and control of failures of soft rock slopes. However, there are few studies on the creep of soft rock slopes which consist of multi-rock and multi-coal seams in 
open-pit mines in the western regions of China such as in the Xinjiang and the Inner Mongolia autonomous regions.

The study site selected for research was based on the east slope of the Dananhu No. 2 open-pit coal mine in the Xinjiang autonomous region. In combination with the topography and engineering profile of the slope of the mining area, the creep deformation law for the soft rock slope was examined using a simulation test and numerical simulation of the bottom friction, the aim being to provide a theoretical basis for the safe and efficient operation of open-pit mines.

\section{Geological conditions of mining area}

The Dananhu No. 2 coal mine is located in the northwest of the Dananhu mining area in Xinjiang province. The exposed strata in the coal mine was formed in the Mesozoic Jurassic, the Neogene and the Quaternary. The surface of the mining area is composed of fine sand, silt, loess, gravel and clay of the Quaternary and Neogene, which collectively consist of loose rock sections with poor stability and brittleness. Most of the strata below the loose layer consist mainly of mudstone, sandy mudstone and coal, followed by sandstone. The strength of rock of the east slope is less than $20 \mathrm{MPa}$. It is known from the definition of soft rock (Cai et al. 2002; He et al. 2012) that the rock belongs to the soft rock category. The Jurassic soft rock is composed mainly of weak surfaces. The argillaceous rock structure is weak and cracked, and the hydrological properties are poor. The rock structure is readily softened after water-rock interaction such that the shear strength is greatly reduced. In the dry and cold climate of the Xinjiang region, due to the rapid changes in temperature, the rock mass is subjected to strong physical weathering after exposure from mining, resulting in secondary fractures, and significant decreases in rock stability.

\section{Rock mechanical strength and creep experiments}

A large amount of monitoring data concerning slope engineering studies in open-pit mines show that the mechanical response of the formation during mining often displays a clear time effect, and the time effect of the deformation will affect the deformation of the slope, which is caused by the rheological properties of the rock layer. The rheology of a rock is a characteristic of the viscous fluid flow that is manifested by deformation over time. (He 2004; Ding et al. 2005; Wang et al. 2009). The Dananhu No. 2 mine is dominated by soft rock; thus the rheological properties are relatively straightforward and predictable.
Therefore, it is of great interest to study the variation of rock and soil strength with time in the Dananhu No. 2 open-pit mine.

\subsection{Experimental scheme}

Combined with the creep properties of soft rock, the uniaxial compression rheological test was performed. The apparatus for performing the creep experiment was the MTS electro-hydraulic servo system shown in Fig. 1. Before the creep test, the rock uniaxial compressive strength test of the rock sample was undertaken to obtain the instantaneous compressive strength of the rock, and this test was used as the basis for estimating the applied load.

The creep curve of the soft rock was obtained by hierarchical loading with the experiment being divided into 7 stages. The stress interval for levels $1-4$ was $1.6 \mathrm{MPa}$. From the 5th level, the interval was $0.8 \mathrm{MPa}$, and the loading stresses were 1.6, 3.2, 4.8, 6.4, 7.2, 8.0 and 8.8 $\mathrm{MPa}$, respectively. The initial displacement value was obtained at the time of the experiment loading, and for the later stages of the experiment, the displacement values were recorded at 20-min intervals.

\subsection{Analysis of results}

The uniaxial creep curve for the mudstone in Fig. 2 shows: the rock-only attenuated creep and the constant velocity creep under the loading stress conditions $1-6$ indicate that

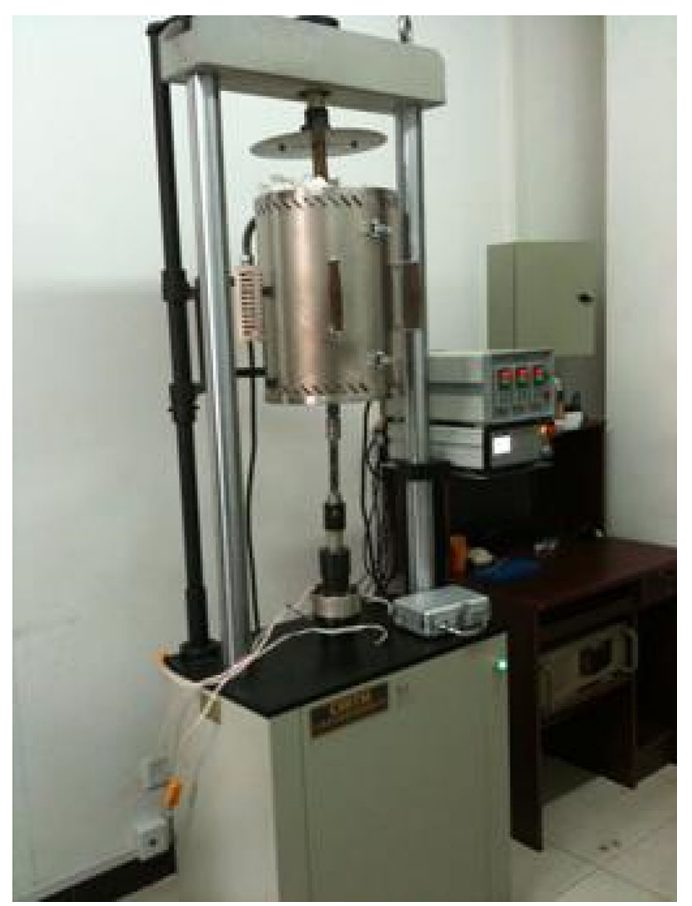

Fig. 1 Experimental system 


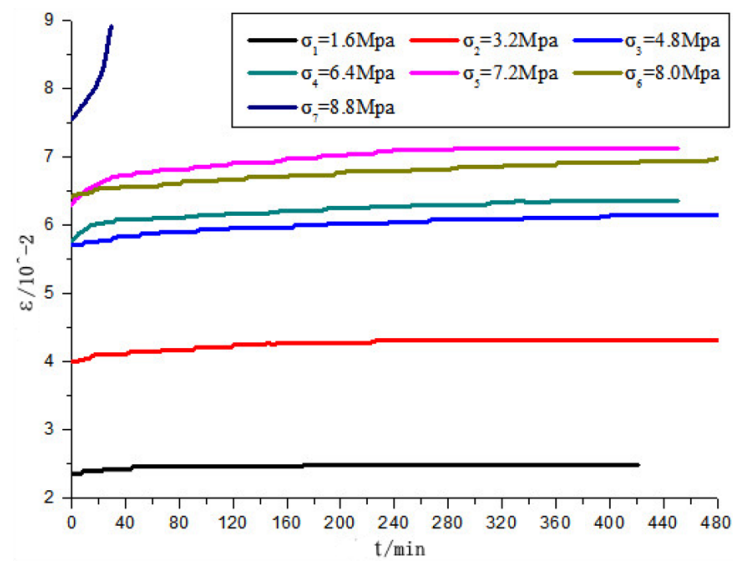

Fig. 2 Uniaxial creep tests for mudstone

the initial stage of creep is small when the constant loading on the rock is small. At the faster speeds, the rock was instantaneously deformed. With increase in time, the deformation of the sample tended to stabilize. When the loading stress reached $8.8 \mathrm{MPa}$, the strain rate of the rock changed rapidly and three stages of creep developed in a short time. Internal cracks developed rapidly, the deformation intensified and the final damage indicated that the creep became unstable.

Therefore, it can be judged that the long-term strength of the soft rock was between 8.0 and $8.8 \mathrm{MPa}$. Under the stress levels of 1-6, the stress was less than the long-term strength, the rock first undergoing instantaneous creep, and then the strain of the rock increased continuously, the rate of deformation gradually decreasing, eventually becoming constant, indicating that the rock creep had terminated, and the creep had stabilized. When the loading stress was greater than the long-term strength of the soft rock, the strain of the rock increased sharply in a short period of time, and cracks were generated in the sample, eventually resulting in breakage and corresponding to unstable creep.

\section{Analysis of creep deformation in a soft rock excavation slope}

\subsection{Numerical analysis}

\subsubsection{Establishment of slope model}

The FLAC3D numerical simulation software was used to establish the geological model for the east slope of the openpit mine. The front and back of the model were constrained by the $Y$-direction displacement. The left and right directions of the model were constrained by the $X$-direction displacement. The bottom of the model was constrained by the Zdirection displacement which formed the displacement boundary and maintained the balance of the system. This simulation used the Mohr-Coulomb constitutive model (Peng 2008; Liu et al 2010) for calculation and analysis; the model of the slope is shown in Fig. 3.

\subsubsection{Mechanical parameters of the rock}

According to the on-site geological exploration data, the lithology of the top and bottom of each coal seam was mainly mudstone, silty mudstone and sandstone, which readily formed a weak layer. The weak layer in the 16-coal seam was mainly mudstone and the weak layers in the 18-, 21-, 22-, 25and 28-coal seams were mostly silty mudstone which were softened when exposed to water. Based on previous experimental data, the physical and mechanical parameters of the rock (soil) of the stratum are given in Table 1.

\subsubsection{Simulation results}

Figures 4, 5, 6, 7 present the numerical simulation results of the east slope. The deformation history of the current slope under gravity stress was studied by analyzing the total displacement cloud map, the displacement vector cloud map, the shear stress cloud map and the plastic zone cloud map.

It can be seen from the total displacement cloud diagram (Fig. 4) and the displacement vector cloud diagram (Fig. 5) that the top surface of the slope has the largest deformation, the displacement vector at the top of the slope is vertically downward, the middle is inclined downward, and the midlower slope has a horizontal shearing trend. These data indicate that the displacement deformation mainly consisted of subsidence. Due to the excavation and unloading, the slope had a tendency to slide along the weak layer. Figure 6 shows that the internal stress distribution of the slope was uniform, and there was no obvious stress concentration; the slope can, therefore, be considered to have been in a stable state; From the plastic map of the slope as shown in Fig. 7, the coal seam and the soft rock of the slope in the weak layer were affected mainly by the shear stress, and also the plastic deformation zone appeared. The slope top was deformed plastically due to the tensile stress and it did not form a weak joint with the internal mudstone. The main deformation of the slope was controlled by the weak layer of mudstone, and the top and bottom parts of

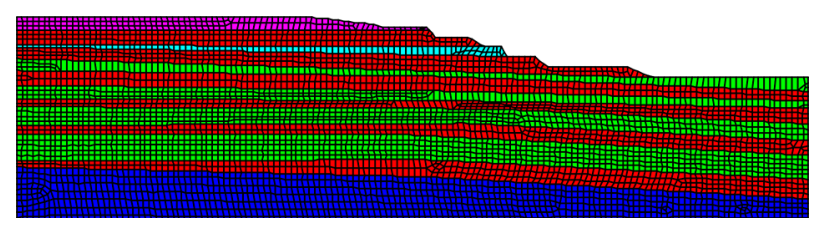

Fig. 3 Present slope model 
Table 1 Mechanical parameters of the rock

\begin{tabular}{lllcl}
\hline Rock mass & Bulk, $K(\mathrm{MPa})$ & Shear, $G(\mathrm{MPa})$ & Cohesion, $C(\mathrm{kPa})$ & Friction angle, $\Phi\left({ }^{\circ}\right)$ \\
\hline Gravel sand & 25 & 11.5 & 4 & 26.8 \\
Mudstone & 400 & 230 & 139 & 18.6 \\
16-Coal & 330 & 160 & 109 & 17.7 \\
Silty mudstone & 280 & 120 & 85 & 17.9 \\
Sandstone & 570 & 340 & 245 & 19.7 \\
\hline
\end{tabular}
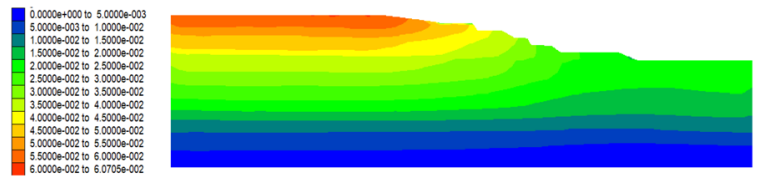

Fig. 4 Total displacement

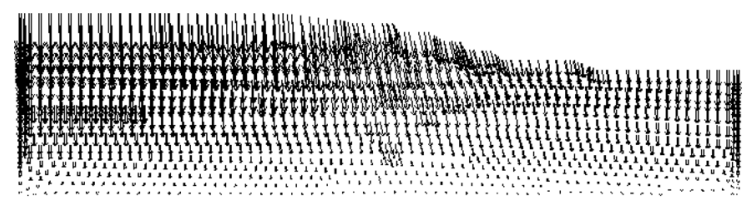

Fig. 5 Displacement vector
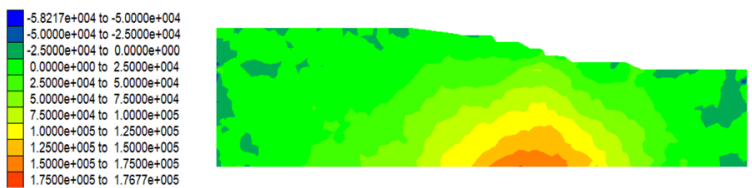

Fig. 6 Shear stress
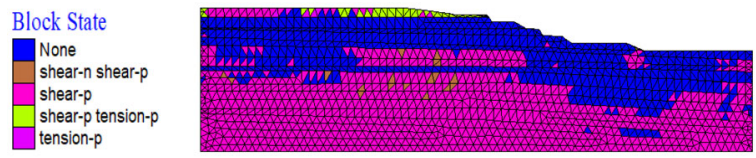

Fig. 7 Plastic zone

the coal seam were the main control sliding surfaces of the slope.

\subsection{Monitoring point displacement analysis}

To study the variation of displacement of the slope under excavation and unloading and gravity stress, monitoring points were arranged at the top, the middle surface and the bottom of the slope. The main monitoring points selected for analysis were 3-2, 3-4, 3-6, 3-7 and 3-8 with the positions of the monitoring points being indicated in Fig. 8 .

From inspection of Fig. 9, it can be seen that the displacement of the monitoring points changed on a stepwise basis. The displacement can be divided into three stages, namely, the slope was affected by the excavation and the unloading and the gravity stress; also the displacement of the initial monitoring point changed slightly, going below the 0 level. Under the influence of excavation, unloading and gravity stress, the displacement increased sharply. After stress redistribution and structural adjustment, the displacement deformation rate slowed down and gradually stabilized, eventually reaching a stable value. Within this, the displacement deformation of monitoring point 3-6 was the maximum, which was due to the presence of the weak coal seam layer and rock below the existing surface of the slope, and which was affected by the shearing displacement of the weak layer of soft rock. This was followed by 3-7 and 3-4; the displacement at 3-8 and 3-2 was small. The lower part of the bench in the bottom of the mining pit was subjected mainly to squeeze displacement caused by the shearing of the soft rock weak layer of the slope. Compared with the area below the top of the slope, deformation was greater.

\section{Similar simulation test for slope of soft rock}

\subsection{Experimental principle and design}

The bottom friction experiment was based on the similarity principle ( $\mathrm{Gu}$ 1995; Wang et al. 2018). When various conditions are similar (geometry, stress, deformation, etc.), friction may be used as a proxy for gravity and then the deformation and failure rules for rock and soil under the action of gravity can be studied. Based on this similarity, the slope similarity model was constructed.

The bottom friction experimental device is illustrated in Fig. 10. A similar material model 2 was placed on the drive belt (steel sheet) 1 which was propelled by an electric motor (manual operation also possible). Thus, when the belt moves in the direction shown in the drawing, the model and the belt will generate friction due to the blocking of the cross bar 4. In this way, the bottom friction model experiment uses friction to simulate the gravity of the rock formation. This happens because the friction 


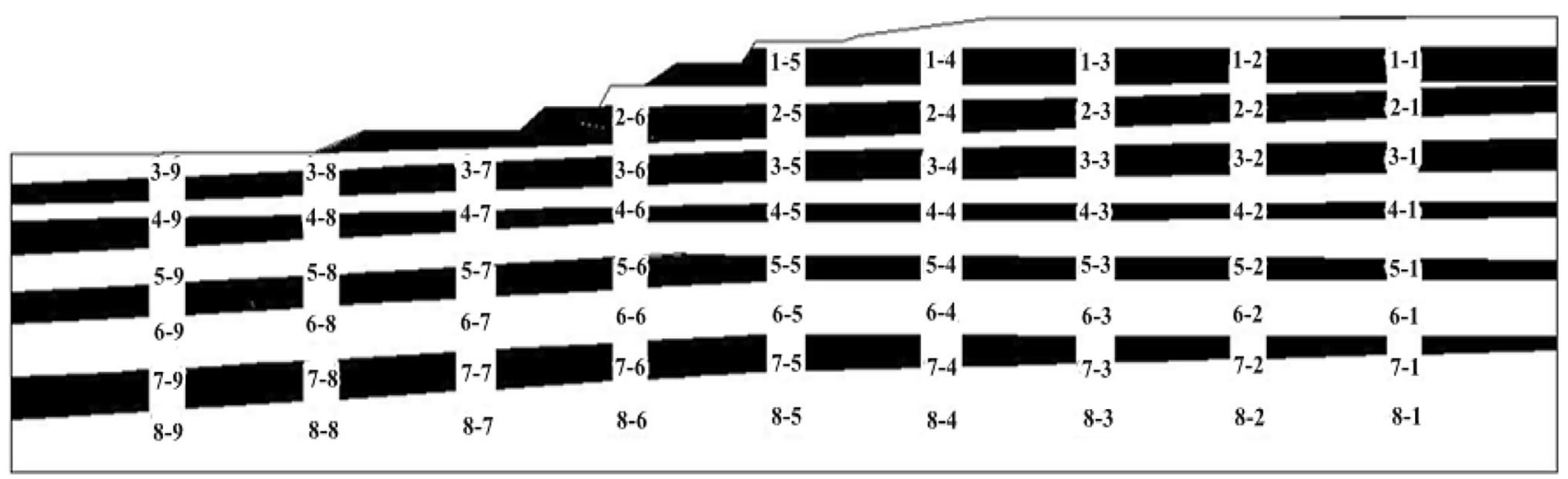

Fig. 8 Layout of the slope displacement monitoring points

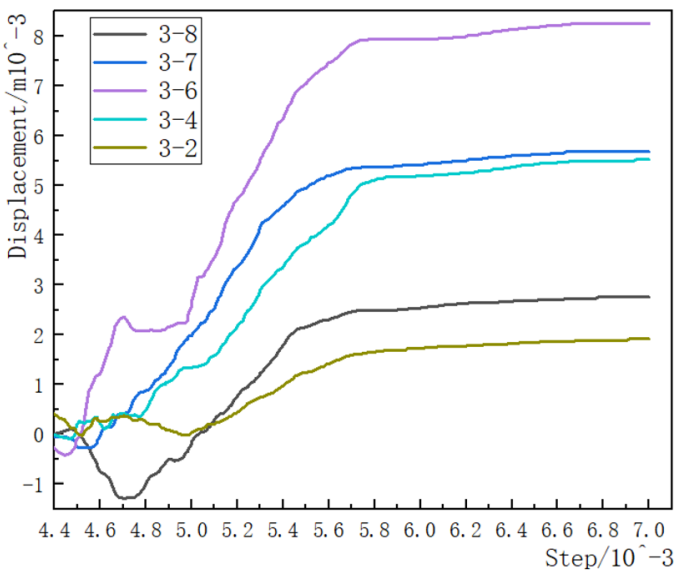

Fig. 9 Displacement variation curves for the monitoring points

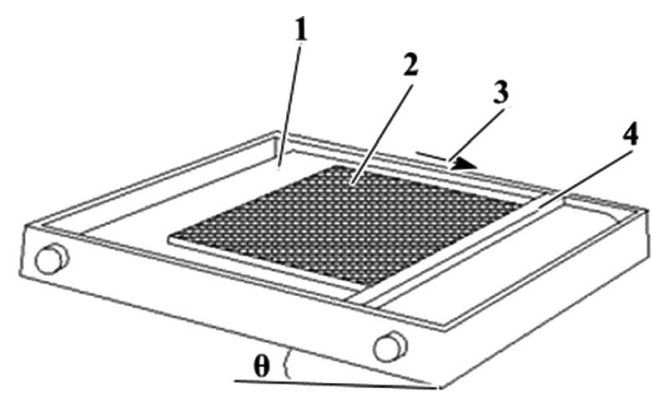

1-Belt 2-Bottom friction model 3-Belt movement direction

4-Fixed crossbar $\quad \theta$ Model inclinatiom

Fig. 10 Bottom friction test device

applied to the surface of the model is in direct contact with the belt. The point where gravity acts should be applied to the intermediate layer of the model along the thickness direction. The thickness of the bottom friction model is generally kept small to reduce the error caused by the frictional force and the point of gravity, thus ensuring the validity of the test.
Regarding the simulation test, the frame size of the bench was $1 \mathrm{~m} \times 0.9 \mathrm{~m}$, fine sand was used as the raw material, and lime and gypsum were used as cementing materials (various proportions) to simulate the slope model. To facilitate the observation of the deformation and the statistical treatment of the results, the model was vectorized and a grid of dimensions $100 \mathrm{~mm} \times 30 \mathrm{~mm}$ grid was marked out on the surface of the model.

\subsection{Experimental process analysis}

The evolution diagram for the deformation of the slope under gravity stress and excavation and unloading are presented in Fig. 11. For a run of $120 \mathrm{~s}$, two cracks corresponding to $\mathrm{S} 1$ and $\mathrm{S} 2$ appeared, which developed at the bottom line of the slope and stretched downwards. When running to $170 \mathrm{~s}$, vertical tension cracks corresponding to S3 appeared along the bottom line of the step. Due to the cutting action of the crack and the weak layer of the coal seam-rock interface, when running to $190 \mathrm{~s}$, three tensile cracks appeared at the top of the slope, that is, S4, and the downward expansion caused partial destruction of the 21-coal seam. The other steps showed successive cracks. After running to $210 \mathrm{~s}$, the slope was decomposed into multiple blocks from the top to the bottom of the $21 \mathrm{st}$ seam, and along the coal seam. The bottom plate was displaced, and the 22-coal seam was also affected by the corresponding fracturing, and there was a tendency to slide.

\subsection{Monitoring point displacement analysis}

To study the deformation law and the damage caused by excavation and unloading and gravity stress of the slope due to creep, the horizontal displacement of the same row of monitoring points was analyzed statistically. The monitoring points selected were $3-2,3-4,3-6,3-7$ and $3-8$ and the results are presented in Fig. 12. 


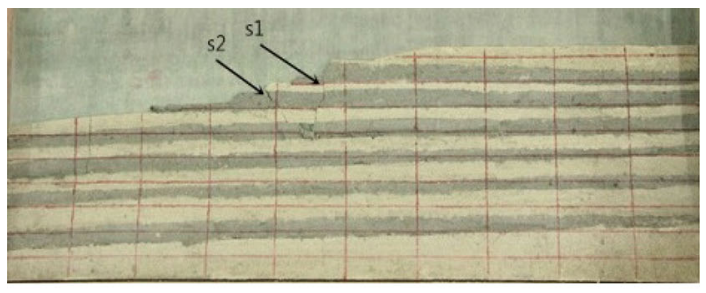

(a) $120 \mathrm{~s}$

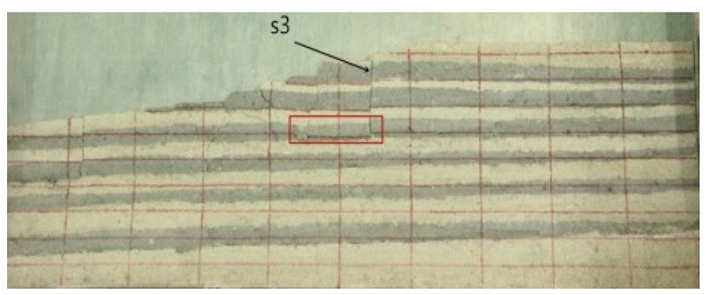

(b) $170 \mathrm{~s}$

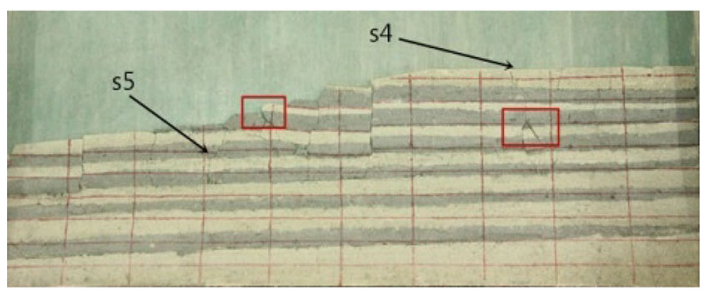

(c) $190 \mathrm{~s}$

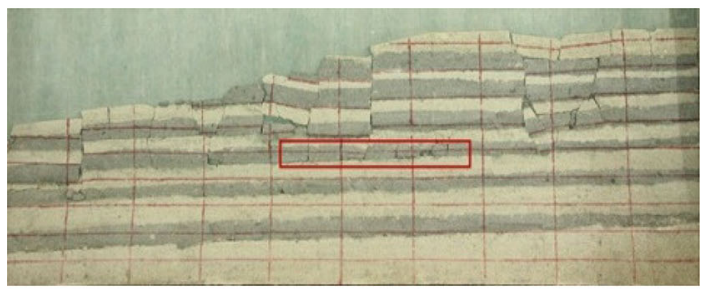

(d) $210 \mathrm{~s}$

Fig. 11 The slope deformation process

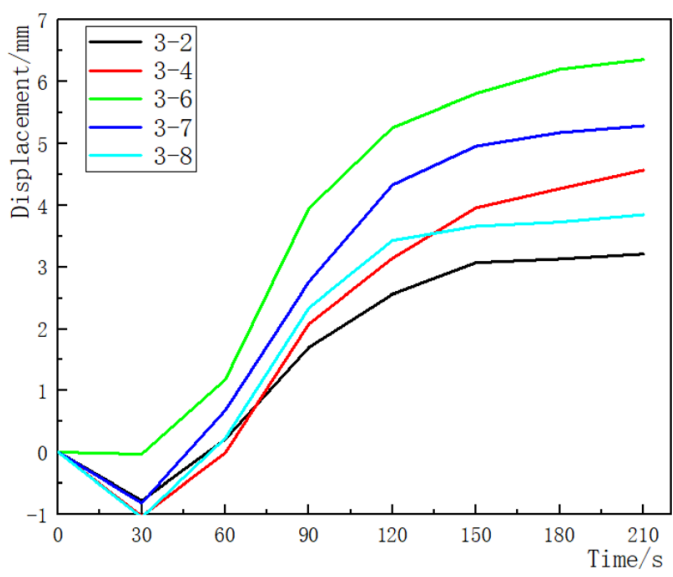

Fig. 12 Displacement variation curves for monitoring points
From the time-displacement curve, the displacement trend was an "S" type curve, the initial displacement fluctuating above 0 , and then increasing rapidly. After a period of time, the displacement began to slow down and gradually reached a specific value, which was consistent with the trend from the numerical simulation. The displacement variations at monitoring point 3-6 was maximum, followed by $3-7$ and $3-4$; the displacement variations for monitoring point 3-2 at the trailing edge of the slope and for 3-8 at the leading edge of the slope were small. The order of the change in the total displacement was as follows: the middle of the slope $>$ the front edge of the slope $>$ the trailing edge of the slope.

These findings indicated that after the excavation, the slope was affected by gravity stress and unloading, such that creep deformation occurred inside the slope, and micro-cracks S1 and S2 were generated inside the slope, and the cracks gradually expanded to the surroundings over time, and the displacement sharply increased. The monitoring points 3-6, 3-4, 3-7 increased gradually as a result of the expansion of the cracks, and 3-6 was most affected. The internal creep of the slope did not extend to the surface of slope, so the displacement at point 3-8 was smaller than that in the slope, but it was still affected by the extrusion displacement of the weak layer of soft rock in the slope. The subsidence deformation of 3-2 was mainly dominated by gravity stress, which had the least impact.

Based on the numerical simulation and the bottom friction similar simulation test results, it has been shown that the cracks of the slope were connected to the lower weak layer by the stress concentration of the east bench, and where the weak layer sheared and underwent creep. The slope relied mainly on its own gravity to generate the sliding force. Due to the horizontal tensile stress of the slope, tensile deformation occurred at the top of the slope, and a tensile failure zone formed. The shear extrusion deformation occurred at the interface between the weak rock and the coal seam. The horizontal displacement had a large amount of deformation, and the rock mass on the upper surface of the slope produced vertical tensile microcracks. Lateral deformation and expansion occurred in the weak layer of mudstone inside the slope. With development of the tensile fracture zone, the rock mass on the upper surface of the slope generated vertical tensile microcracks. The tensile cracks gradually penetrated into the horizontal slip surface, which led to further development of the slope deformation, and there was the tendency for sliding to occur along the bottom of the slope. Therefore, the deformation of the eastern slope was mainly controlled by the weak layer of mudstone, and the 22-coalseam roof was the main sliding surface of the slope. The deformation was dominated by the extension of the vertical tensile crack 
and the shearing of the soft layer. The slope slide was of the creep-cracking mode.

\section{Analysis of the slope creep law for soft rock}

\subsection{Relationship between stress variation and displacement for the excavation slope of soft rock}

According to the uniaxial compression creep experiment for mudstone and the slope deformation in the similar simulation experiment, the shear creep deformation of the slope for layered soft rock has great influence on the slope stability, thus it is necessary to study the area of the creep (Fan and Gao 2007; Fan et al. 2010). Through analysis of the FLAC3D numerical simulation and the bottom friction test, the stress-displacement curve and the displacementtime curve for the monitoring points were analyzed. Thus, it was possible to establish the corresponding relationship between the stress and strain and the displacement deformation of the slope of the soft rock as shown in Fig. 13. Slope deformation can be divided into four stages: the initial deformation stage, the initial creep stage, the constant velocity deformation stage and the deceleration deformation stage. The analysis further revealed the deformation law for the slope of the soft rock in the Gobi region.

The initial deformation stage $(O-A)$ : the slope stress increased rapidly and was in a stage of elastic deformation. Due to the excavation and unloading, the stress in the slope direction increased, and the stress concentration occurred locally at the foot of the eastern slope of the bench, and micro-cracks appeared. After the stress was reduced slightly, the slope entered the creeping stage.
The initial creep stage $(A-B)$ : the deformation at this stage was mainly caused by the closure of micro-cracks closure and the structural adjustment. Due to the influence of gravity stress, the lower weak layer was compacted, and the rate of the deformation decreased with time, so that the curve bent in a downward direction. The displacement still increased and was accompanied by small amounts of micro cracks.

The constant velocity deformation stage $(B-C)$ : the slope stress continuously adjusted and changed, and the internal damage effect of the slope was enhanced, so that the micro cracks began to expand, increasing continuously and evenly in a downward direction; this made the horizontal displacement of the creep zone increase. Therefore, compared with the $A-B$ segment, the deformation rate increased.

The deceleration deformation stage I $(C-D)$ : Point $C$ was the turning point. After point $C$, the internal structure of the slope re-adjusted, the plastic deformation of the slope weakened and the velocity of the creeping movement slowed down. The macroscopic performance showed that the displacement rate of the slope decreased compared with the constant velocity deformation stage.

The deceleration creep stage II $(D-E)$ : After point $D$, the displacement rate was further reduced and tended to zero after point $E$, and where there was no risk of landslide.

\subsection{Slope creep evolution model for soft rock}

The study of slope creep for soft rock (Tian et al. 2018) is often based on the instability of the slope; that is, the slope has eventually been destroyed prior to the landslide occurring. The deformation process generally includes a transient deformation phase, an initial deformation phase, a constant velocity deformation phase and an accelerated deformation phase. Due to the excavation and unloading

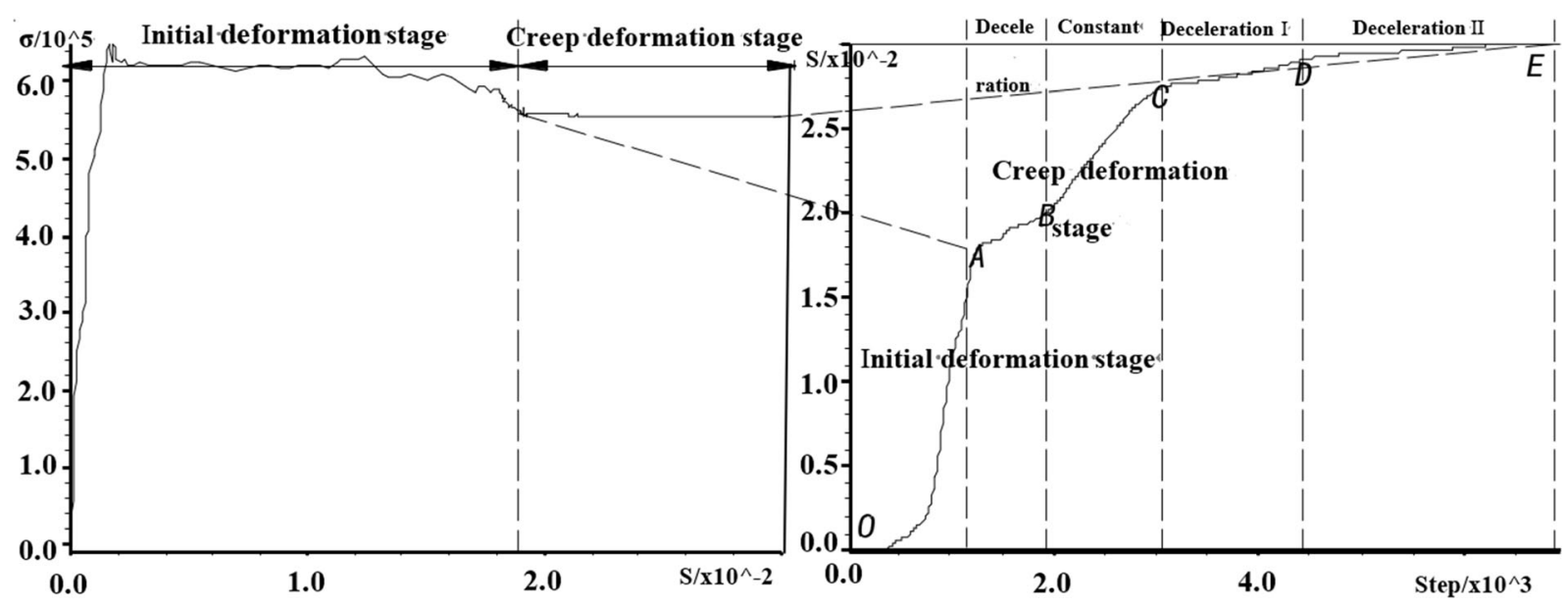

Fig. 13 Deformation process of creep zone 
and gravity stress on the slope, the slope has different levels of deformation. When the slope anti-sliding force is greater than the sliding force, the slope can still be in a stable state. Therefore, based on the simulation results and the creep deformation law of the original unstable slope ( $\mathrm{Li}$ et al. 2013; He et al. 2016), the creep deformation law for a stable slope is proposed, and the original creep model has been improved, obtaining a stable creep slope. The slip evolution model is shown in Fig. 14.

An initial deformation state $(O-A)$ : This stage corresponds mainly to the elastic deformation stage; and the slope deformation does not enter the creep stage. The effect of the sliding force is mainly related to the structure and is not affected by time.

An initial creep state $(A-B)$ : From point $A$, the slope enters the creep state. Due to the compaction and structural adjustment of the rock mass, an elastic effect occurs after deformation, and the creep rate decreases with time, and this is smallest at point $B$.

A stable creep state $(B-C)$ : The adjustment of the slope stress induces the crack to increase in a regular manner, and the strain rate remains unchanged at this stage.

A deceleration creep state I $(C-D)$ : In the process of deformation, point $C$ is the turning point. Given that a landslide failure condition is absent, a plastic deformation occurs gradually and its rate decreases.

A deceleration creep state II $(D-E)$ : After point $D$, the deformation decreases further, the deformation rate gradually decreases and tends to zero. After point $E$, the slope is in a stable state.

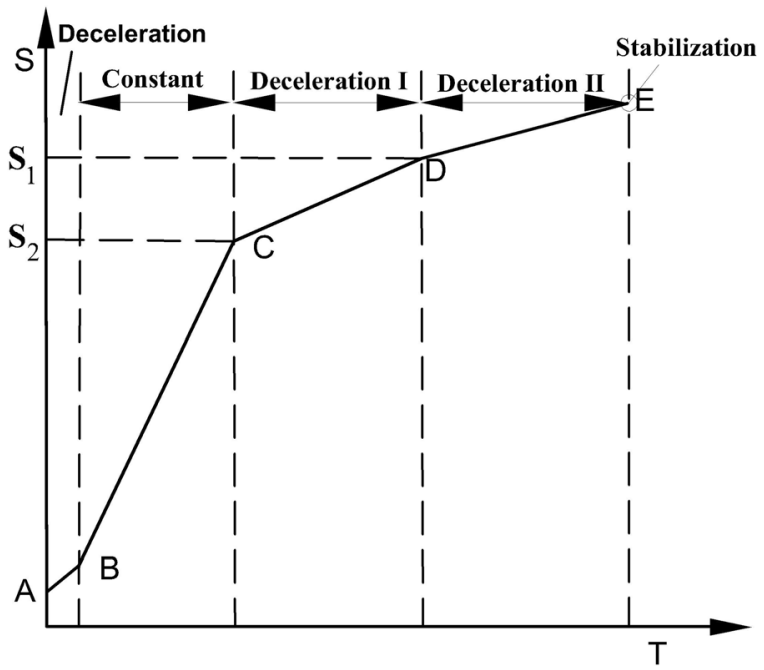

Fig. 14 Schematic of the slope creep evolution model

\section{Conclusions}

(1) The long-term strength of mudstone is between 8.0 and $8.8 \mathrm{MPa}$ in the Gobi area of Xinjiang. When the soft rock slope is in a low stress state, the deformation corresponds to stable creep.

(2) The numerical simulation and bottom friction experiments show that creep deformation of the eastern slope in the Dananhu open-pit mine was mainly controlled by the weak mudstone layer, especially by the material located on the roof and the floor of the coal seam. Also the sliding mode of the slope was creep and tension cracking.

(3) The stable creep deformation can be divided into four stages: the initial deformation stage, the initial creep stage, the constant velocity deformation stage and the deceleration deformation stage.

(4) In the process of stable creep deformation, point $C$ in the stress-displacement deformation curve was the critical point. The trend of deformation after point $C$ was the key to determining whether the slope was stable. If the deformation rate after point $C$ decreases, the slope will be in a stable creep condition.

Acknowledgements The work was Supported by State Key Laboratory for Geomechanics and Deep Underground Engineering, China University of Mining and Technology, Beijing (No. SKLGDUEK1923) and National Key Research and Development Program (No. 2018YFC0808301).

Open Access This article is licensed under a Creative Commons Attribution 4.0 International License, which permits use, sharing, adaptation, distribution and reproduction in any medium or format, as long as you give appropriate credit to the original author(s) and the source, provide a link to the Creative Commons licence, and indicate if changes were made. The images or other third party material in this article are included in the article's Creative Commons licence, unless indicated otherwise in a credit line to the material. If material is not included in the article's Creative Commons licence and your intended use is not permitted by statutory regulation or exceeds the permitted use, you will need to obtain permission directly from the copyright holder. To view a copy of this licence, visit http://creativecommons. org/licenses/by/4.0/.

\section{References}

Cai MF, He MC, Liu DY (2002) Rock mechanics and engineering. Science Press, Beijing, pp 112-119 (in Chinese)

Ding XL, Fu J, Liu J (2005) Study on creep behavior of alternatively distributed soft and hard rock layersand slope stability analysis. Chin J Rock Mech Eng 19:12-20

Fan QZ, Gao YF (2007) Study on creep properties and nonlinear model of soft rock. Chin J Rock Mech Eng 02:391-396

Fan QY, Yang KQ, Wang YM (2010) Study on creep mechanism of mud soft rock. Chin J Rock Mech Eng 29(08):1555-1561 
Gu DZ (1995) Equivalent materials and similitude models. China University of Mining and Technology Press, Xuzhou, pp 103-109

He YM (2004) Study on the creep model and creep mechanism of rock slope. Chinese Society of Rock Mechanics and Engineering. In: Proceedings of the 8th national conference on rock mechanics and engineering. Chinese Society of Rock Mechanics and Engineering, p 6

He MC, Jing HH, Sun XM (2012) Engineering mechanics of soft rock. Science Press, Beijing, pp 10-12

He KQ, Chen WG, Zhang P (2016) Real-time monitoring of dynamic stability coefficient of creeping slope and its displacement early warning criterion. Chin J Rock Mech Eng 35(7):1379-1384

Li SY, LüS L, Zhang CX (1998) Analysis on monitoring data and creeping mechanism for the hillside of a project. Chin J Rock Mech Eng 17(2):133-139

Li HZ, Yang TH, Xia D et al (2013) Analysis of dynamic stability of slope based on rheological properties of soft rock. J Northeast Univ (Natl Sci) 34(02):293-296

Liu HD, Mao CL, Guan YP (2010) Analysis method and numerical simulation for slope stability. J Water Resour Archit Eng 8(3):101-102

Peng WB (2008) Practical tutorial of FLAC3D. Mechanical Industry Press, Beijing

Tan WP, ZhengY R, Wang K (2010) Stable state of landslides considering creep properties. Chin J Geotech Eng S2:5-8
Tian HM, Chen WZ, Tian T et al (2018) Experimental and theoretical studies of creep damage behavior of soft rock. Chin J Rock Mech Eng 46(10): 125-129

Wang YF (2009) Analysis of creep deformation mechanism based on inclinometer monitoring results. Chin J Rock Mech Eng 28(1):212-216

Wang GX, Xu JL, Liu GD et al (2007) Sliding prevention and control technology. China Railway Publishing House, Beijing

Wang LG, Zhao N, He F et al (2009) Rock creep damage model and its stability analysis. J China Coal Soc 34(01):64-68

Wang ZW, Wang LG, Wang JG et al (2010) Study on deformation mechanism and control technique of creeping slope with weak plane. J Liaoning Techn Univ (Natl Sci) 29(2):197-200

Wang XC, Guan XM, Du MQ et al (2013) Analysis of sliding mechanism and stability of creep area of Antaibao open-pit mine slope. J China Coal Soc 38(S2):312-318

Wang Y, Sun M, Guo P et al (2018) Experimental study on numerical simulation of creep characteristics for soft rock of similar model. Coal Sci Technol 46(10):125-129

Xu B (2017) Study on deformation characteristics of instability and sliding model of creep landslide. Doctoral Thesis, University of Science and Technology, Beijing

Yang TH, Rui YQ, Li LC et al (2003) Study on deformation mechanism and dynamic stability of bedding creeping slope. J Eng Geol 11(2):155-161 